\title{
A Numerical Study on the Thermal and Strain Characteristics of EGR Cooler
}

\author{
Foad Vashahi ${ }^{1}$, Myungjae Lee ${ }^{2}$, Jintaek Kim ${ }^{3}$, Daesuk Kim ${ }^{4}$ and Byung Joon Baek ${ }^{5}$ \\ ${ }^{1}$ Division of Mechanical System Eng. Chonbuk National University, Korea \\ ${ }^{2}$ Division of Mechanical System Eng. Chonbuk National University, Korea \\ ${ }^{3}$ Division of Mechanical System Eng. Chonbuk National University, Korea \\ ${ }^{4}$ Division of Mechanical System Eng. Chonbuk National University, Korea \\ ${ }^{5}$ Division of Mechanical System Eng. Chonbuk National University, Korea \\ ${ }^{1}$ foadvashahi@outlook.com, ${ }^{2}$ lmj91@hanmail.net, ${ }^{3} \mathrm{kjtaek}$ @bnu.ac.kr, \\ ${ }^{4}$ dashi@jbnu.ac.kr, ${ }^{5}$ baekbj@jbnu.ac.kr
}

\begin{abstract}
The Exhaust-Gas Recirculation (EGR) is the effective method to reduce the exhausted $N O_{x}$ from diesel engine. The EGR system needs to be cooled to lower the combustion temperature, which results in the reduced engine power. To improve the performance of EGR Cooler, maximizing heat transfer coefficient, heat transfer area and corrosion resistant material should be considered while the thermal stress produced by the temperature difference between exhaust gas and coolant is also considered as a highly important factor from the point of safety operation. The thermo-flow characteristics inside the EGR Cooler and surface temperature have been investigated by using CFD code STAR-CCM+9.0. Finally, as a result of the simulation, the stress location and crack spots has been experimentally observed and compared with simulation. The focus is going to be mainly on CFD simulation and flow behavior inside the EGR which is considered important in order to improve the efficiency.
\end{abstract}

Keywords: EGR Cooler, Heat Transfer, CFD, Thermal stress, Mass flow rate

\section{Introduction}

The harmful effect of $\mathrm{NO}_{\mathrm{x}}$ emissions, produced by internal combustion engines due to the defective ignition, to health and environment is unavoidable, yet it may can be reduced. The mechanism of reducing the $\mathrm{NO}_{\mathrm{x}}$ emissions has been investigated by several scientists $[1,2]$. They all pointed out that in order to reduce the $\mathrm{NO}_{\mathrm{x}}$ emissions lowering combustion flame temperature is needed. To reach this goal, the exhaust gas recirculation (EGR) technique has been introduced and found as an effective way to reduce the $\mathrm{NO}_{\mathrm{x}}$ emission in automotive industries. This process is mostly done by using a heat exchanger (mostly shell and tube heat exchanger), exhaust gas flowing inside the tube and coolant in the shell.

EGR systems can be classified into different categories. The most important one of them is based on cooled or hot EGR [3]. In cooled EGR, the exhaust gas introduced to intake directly after being cooled down. The characteristics of this system are, lower $\mathrm{NO}_{\mathrm{x}}$, better knock suppression, complex structure, and higher cost. It also increases the density and mass flow rate of the intake charge [4]. On the other hand, in hot EGR, air will be heated by the recirculated exhaust and it will be recycled directly to intake. Usually engines which are using hot EGR achieve higher thermal performance due to the higher combustion. It also should 
point out that the use of cooled EGR is more effective rather than hot EGR in case of $\mathrm{NO}_{\mathrm{x}}$ reduction $[5,6]$.

CFD simulation has been proven as a non-expenditure and relatively precise procedure in improving design factors. EGR coolers were also numerically studied by several scientists. Wang et al., [7] modeled a simple EGR and studied the effect of tank shapes. They found out that just by applying different tank design the thermal efficiency can be increased. Also a comparison between experimental and simulation result in case of fouling and deposit formation has been given by Florea et al., [8] which proves the CFD as a highly recommended solution in case of studying EGR.

With all those being said, it seems that there is a need for a comprehensive CFD simulation analysis, in order to study parametric design factors. As far as this paper concerns, a CFD simulation using STAR CCM+ version 9.0 is performed for and EGR cooler, shell and tube type, and design factors such as tube type or mass flow rate and its effects has been studied. Also the stress location and crack spots has been experimentally observed and compared with simulation. The focus is going to be mainly on CFD simulation and flow behavior inside the EGR which is considered important in order to improve the efficiency.

\section{Analysis Model}

An EGR Cooler with 37 tubes, $163 \mathrm{~mm}$ length, categorized in shell-and-tube heat exchanger type is used. The EGR cooler consists of three major parts, inlet and outlet tanks, coolant region or shell, and tubes. Detailed EGR parts can be seen in Figure 1. Hot exhaust gas flows inside the tubes while the shell part contains the coolant. Figure 2 shows the generated polyhedral mesh in fluid region using commercial software STAR CCM+ 9.0. Total cell number is about 2,100,000 considering three prism layers for fluid region to achieve more realistic and precise answer. Fluid region, which is separated in two parts of coolant and gas regions, is interacted with the solid region performing the conjugate heat transfer. Existing the convection heat transfer on the outer solid wall, requires the suitable boundary condition on outer solid boundaries indeed. In case of parametric study two different tube types as plain and spiral with outside diameter and thickness of 6.4 and $0.35 \mathrm{~mm}$ respectively is being considered. Spiral tube fabricated with a pitch of 3.5 and helix length of $143 \mathrm{~mm}$.

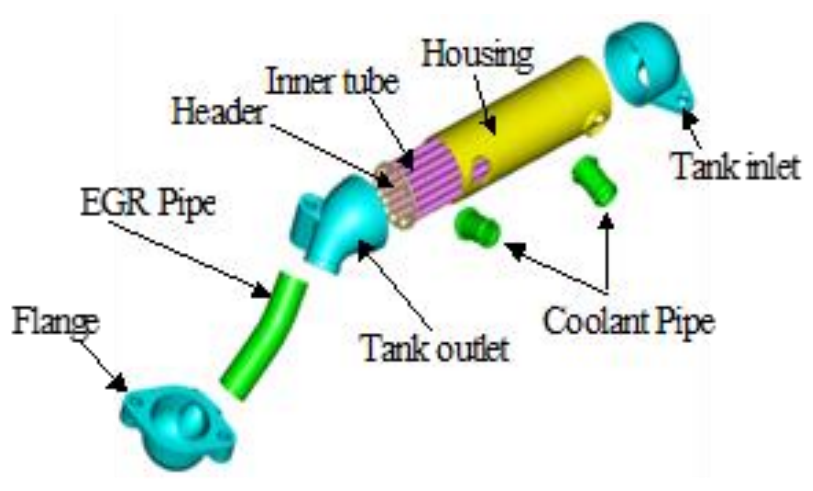

Figure 1. Component of EGR Cooler 


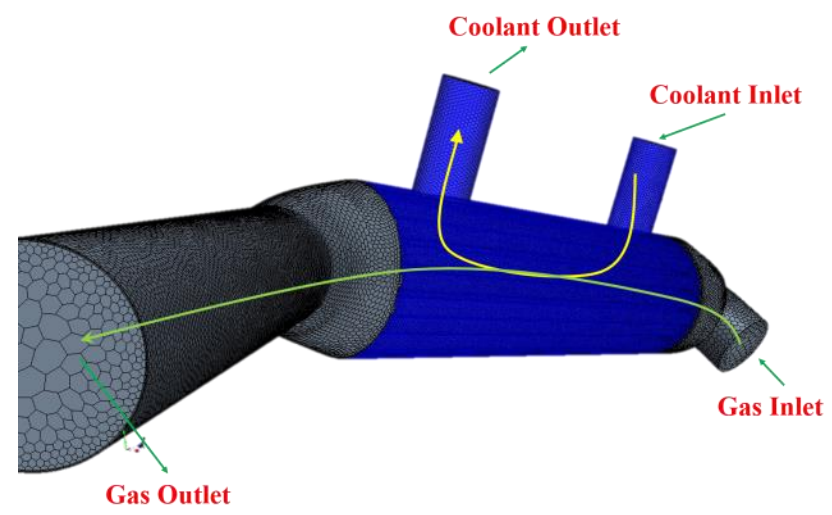

Figure 2. Mesh Model for Fluid Region

\section{CFD Analysis and Boundary Conditions}

A CFD simulation is performed by the STAR CCM+ Ver.9.0 in order to study the flow behavior in EGR. To validate the answer, results are compared to that of experiment [9]. The simulation performed based on the experimental boundary conditions as well. As mentioned above, convection boundary condition is needed on the outer solid wall. Thus, the convection heat transfer condition on the solid outer boundaries is chosen with air heat transfer coefficient of $20 \mathrm{~W} / \mathrm{m}^{2} \mathrm{~K}$ and temperature is set to $25^{\circ} \mathrm{C}$, to simulate the experimental condition. Among the two equation models, the Turbulence $k-\varepsilon$ model (most popular turbulence model) with $\mathrm{y}+$ wall treatment is selected. The efforts to develop this model was done by several scientists since 1945 but it is known that the reference paper is that by Joens and Launder (1972) [10]. This is the model which referred as the Standard $k-\varepsilon$ model. Launder and Sharma by 1974 retuned the model's closure coefficients. The standard turbulence $k-\varepsilon$ is defines as follow:

Eddy Viscosity

$\mu_{T}=\rho C_{\mu} \frac{k^{Z}}{\varepsilon}$

Turbulence Kinetic Energy

$\rho \frac{\partial \mathrm{k}}{\partial \mathrm{t}}+\rho U_{j} \frac{\partial \mathrm{k}}{\partial x_{j}}=\tau_{\mathrm{ij}} \frac{\partial \mathrm{U}_{\mathrm{i}}}{\partial x_{j}}-\rho \varepsilon+\frac{\partial}{\partial x_{j}}\left[\left(\mu+\mu_{T} / \sigma_{k}\right) \frac{\partial \mathrm{k}}{\partial x_{j}}\right]$

Dissipation Rate

$\rho \frac{\partial \varepsilon}{\partial \mathrm{t}}+\rho U_{j} \frac{\partial \varepsilon}{\partial x_{j}}=C_{\varepsilon 1} \frac{\varepsilon}{k} \tau_{\mathrm{ij}} \frac{\partial \mathrm{U}_{\mathrm{i}}}{\partial x_{j}}-C_{\varepsilon 2} \rho \frac{\varepsilon^{2}}{k}+\frac{\partial}{\partial x_{j}}\left[\left(\mu+\mu_{T} / \sigma_{\varepsilon}\right) \frac{\partial \mathrm{k}}{\partial x_{j}}\right]$

Closure Coefficient

$C_{\varepsilon 1}=1.44, C_{\varepsilon 1}=1.92, C_{\mu}=0.09, \sigma_{k}=1.0, \sigma_{\varepsilon}=1.3$ 
Segregated Flow, Segregated Fluid Temperature with a constant density in a steady state condition has been chosen. Simulation has been run up to 2000 iteration so that the convergence in solution observed [11]. In case of material $\mathrm{H}_{2} \mathrm{O}$ considered as coolant, air with specification of $0.493 \mathrm{~kg} / \mathrm{m}^{3}, 0.051 \mathrm{~W} / \mathrm{m}-\mathrm{K}$ for density and thermal conductivity respectively is used while the solid part defined with Stainless steel.

\section{Experimental Setup}

The experimental setup consists of EGR gas and coolant parts as shown in Figure 3. Heated air is supplied through the cooler and filter to make the air clean and dry. The inlet temperature and mass flow rate of the air is controlled by the heater and flow meter. Thermal performance such as, the heat transfer rate, outlet temperature of the cooler, and pressure drop is measured as a function of gas temperature and mass flow rate at a fixed charged air flow condition. Photo 1 shows the constructed test apparatus for thermal shock experiment. In this experiment, the heating and cooling process is repeated to find the location of crack due to the thermal shock on the cooler Table 1 represents the operational conditions for charge air and cooling air used in experiment.

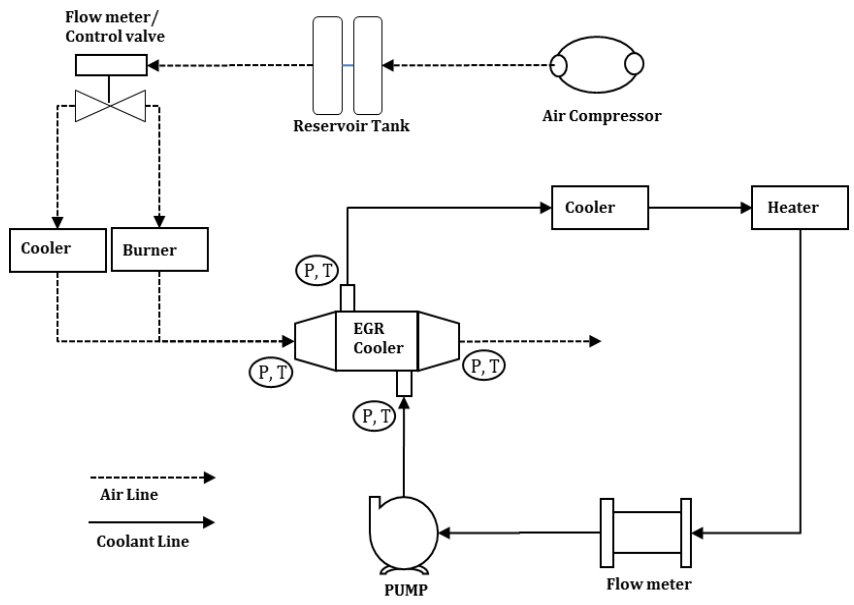

Figure 3. Schematic of Experimental Setup

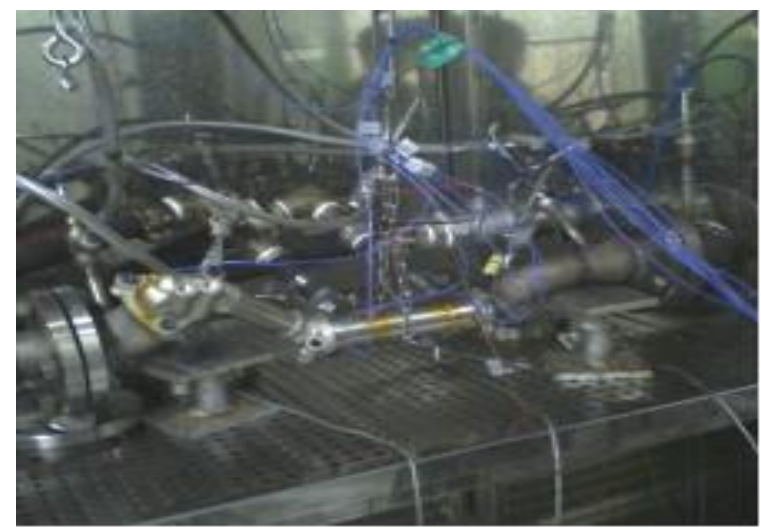

Photo 1. Test Apparatus of Thermal Shock 
Table 1. Operational Condition for Performance test of EGR Cooler

\begin{tabular}{l|c|c}
\hline \multicolumn{1}{c|}{ Boundary Condition } & EGR Gas & Coolant \\
\hline Volume Flow Rate [L/min] & & 20 \\
Mass Flow Rate [kg/h] & 72 & \\
Temperature [K] & 673 & 353 \\
Pressure [Bar] & 1 & \\
\hline
\end{tabular}

\section{Results and Discussion}

The comparison between experimental and simulation result for EGR with spiral tube can be found in Table 2. It indicates that results are in good agreement with that of experimental with approximately of $4 \%$ error in coolant heat transfer. This emphasizes on the fact that the simulation is reliable to study the EGR and improve its performance and efficiency through CFD.

Table 2. Comparison between Experimental and CFD Results

\begin{tabular}{c|c|c|c|c}
\hline TITLE & $\begin{array}{c}\text { Gas Outlet } \\
\text { Temperatuer }\end{array}$ & $\begin{array}{c}\text { Coolant Outlet } \\
\text { Temperatuer }\end{array}$ & $\begin{array}{c}\text { Gas Side Heat } \\
\text { Transfer }\end{array}$ & $\begin{array}{c}\text { Coolant Side } \\
\text { Heat Transfer }\end{array}$ \\
\hline Experiment & $157.5{ }^{\circ} \mathrm{C}$ & $89.8{ }^{\circ} \mathrm{C}$ & $5172.925 \mathrm{~W}$ & $5091.195 \mathrm{~W}$ \\
CFD & $155.8{ }^{\circ} \mathrm{C}$ & $89.1{ }^{\circ} \mathrm{C}$ & $5017.434 \mathrm{~W}$ & $4864.964 \mathrm{~W}$ \\
CFD Error\% & $1 \%$ & $1 \%$ & $3 \%$ & $4 \%$ \\
\hline
\end{tabular}

Figure 4 represents the decreased temperature in three different tubes in gas region in EGR Cooler along the flow direction and temperature increase in coolant region while Figure 5 shows the non-uniformity of temperature gradient on a cut section. Hot gas temperature decreases gradually from inlet to outlet in gas region for about $250{ }^{\circ} \mathrm{C}$ as it is interacting with coolant region through conjugate heat transfer which results in increase in coolant region temperature from 85 to $89{ }^{\circ} \mathrm{C}$. It can be noticed that the fact that water has a higher heat capacity, resulted to a lower temperature difference while there is a significant temperature difference in the gas side due to smaller heat capacity. Concluding from both Figure 4 and 5 it has been observed that the higher temperature region belongs to the top most tube, center and then bottom tube sequentially. This is happening due to the flow distribution in inlet tank and the mass flow rate division inside the tubes.

Figure 6 shows the flow distribution on a cut section next to the entrance of tubes. It can be seen that the flow is concentrated at the top and right side of the inlet tank. A giant recirculation area is observed due to the inlet tank design. These areas can be led to a higher pressure drop and less heat transfer, consequently it lowers the efficiency of the device. Also it can be seen that these areas will affect the flow at the entrance of the tubes especially at the center due to the vortex stream of high temperature exhaust gas. Referring to Figure 7 


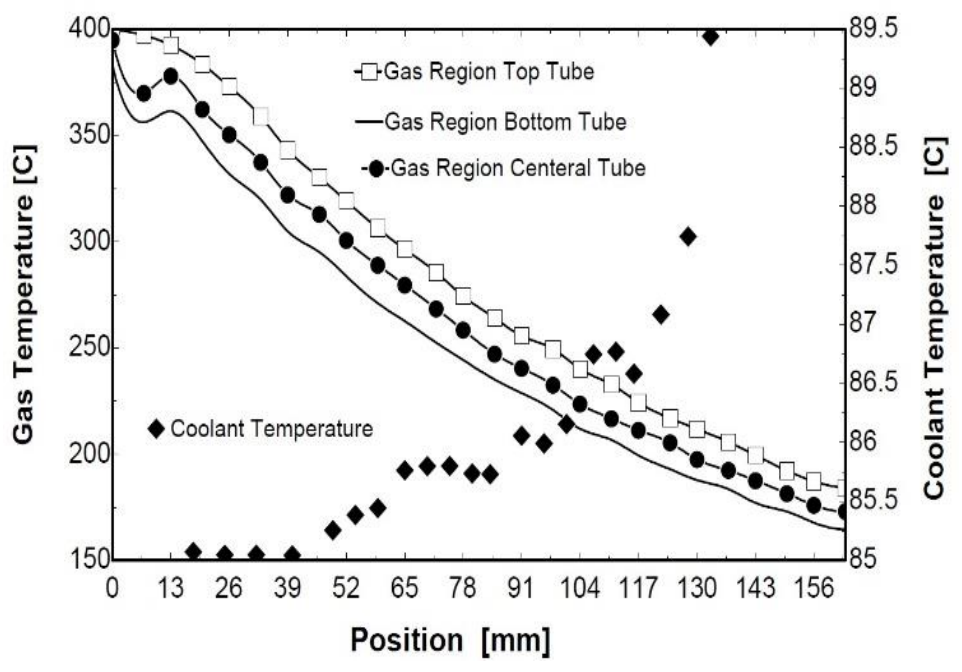

Figure 4. Temperature Gadient in EGR

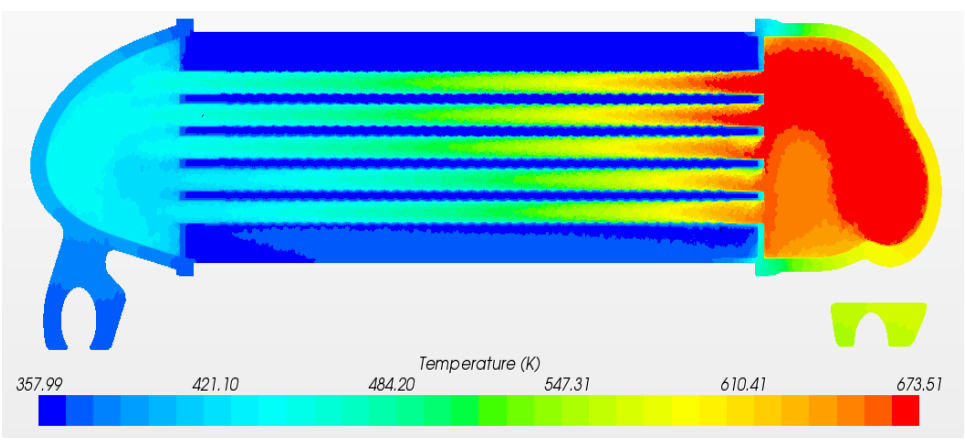

Figure 5. Temperature Gadient in EGR on a Cut Section

illustrating the mass flow division through the tubes separated into two parts of right and left side of the header, it is understandable that the right side with an average of $0.001458 \mathrm{~kg} / \mathrm{s}$ of mass flow contains higher volume of flow rather than that of left side with an average of $0.000898 \mathrm{~kg} / \mathrm{s}$. Thus the tube pattern and flow division can be considered as an important design factor. Fouling and clogging which will happen due to the particle matters repletion in tubes is considered as another negative effect of this areas since it provides a suitable bed for more fouling which in sever conditions will results in clogging and decreasing the EGR performance.

The comparison of EGR with spiral tube and plain tube has been demonstrated in Figure 8. It compares the effect of mass flow rate change on both EGRs in gas region. Mass flow rate changed from 0.17317 to $0.51952 \mathrm{~kg} / \mathrm{s}$ by intervals of 0.25 . Simulation results in both spiral and plain tube, indicates that increase in mass flow rate will increase the amount of heat transfer. Considering likely same slope for both tubes, yet this increase in EGR with spiral tube (dot line) is occurred at higher level and depicts a higher heat transfer in gas region for about an average of $16 \%$. This also will result in lower gas outlet temperature in spiral tube for about $22 \%$ (square dot line) in compare to that of plane tube. This will also justifies the higher amount of heat transfer and lower outlet temperature in gas region since the turbulence 
will increase the heat transfer. Also in EGR with spiral tubes, there would be more heat transfer due to the higher heat transfer rate as has been expected. As a matter of Pressure

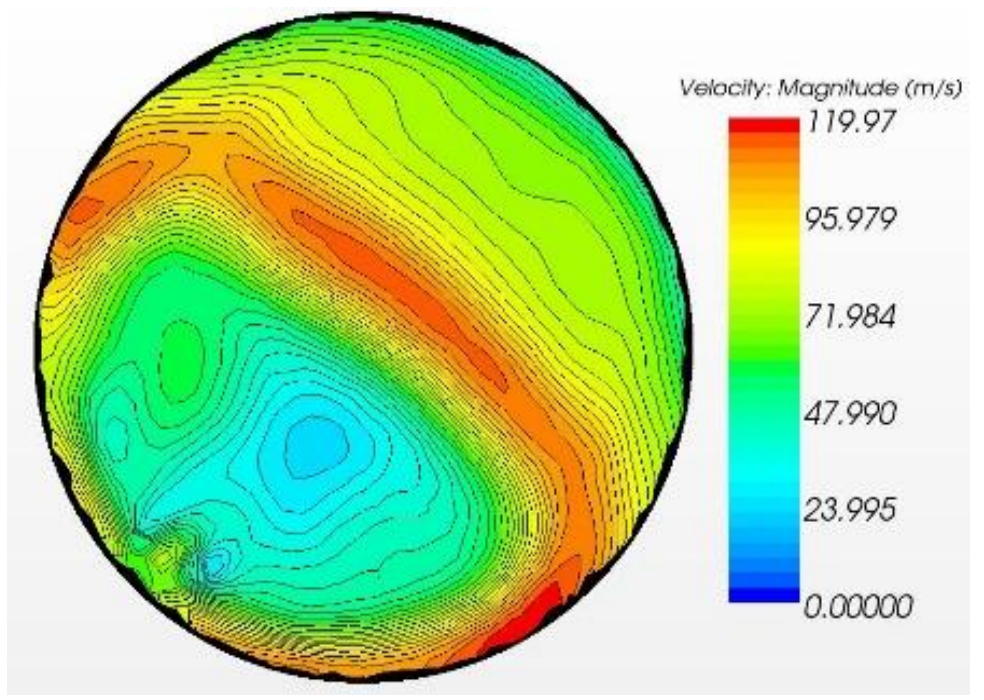

Figure 6. The velocity Distribution Next to the Tubes Inlet

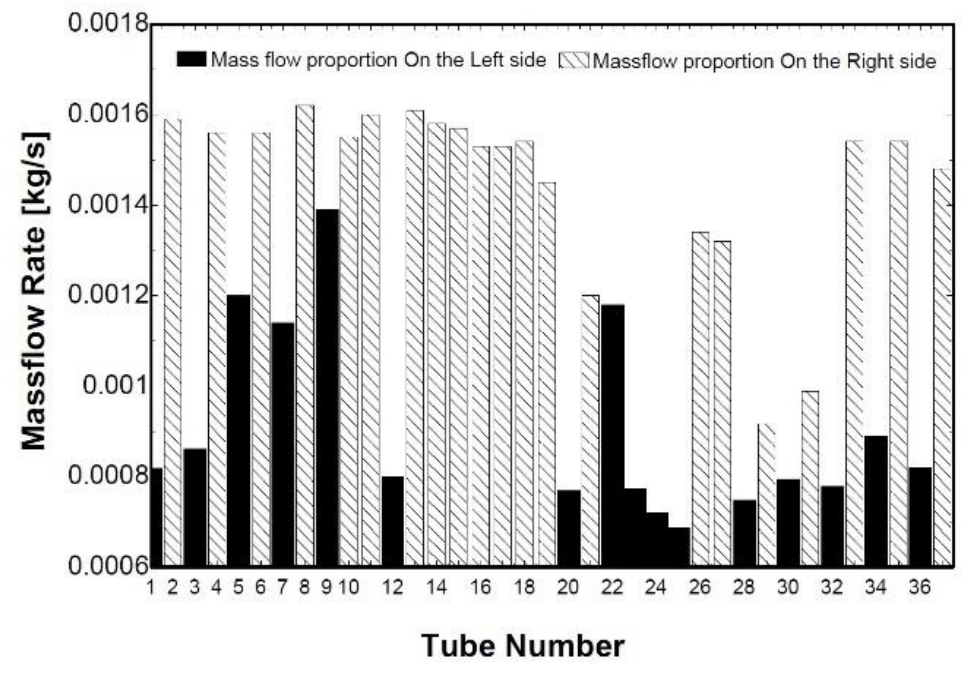

Figure 7. Mass Flow Division i Tubes

drop, in EGR with plain tube measured pressure difference is 0.0169 bar from inlet gas to outlet while the amount of 0.0404 bar is being seen for that of EGR with spiral tube. Clearly this increase in pressure drop achieved due to a higher turbulence ratio in spiral tubes because of the helix shape of the tubes. Thus, to design an EGR with higher heat transfer rate we need to use spiral tubes, meanwhile the pressure drop will be increased due to the turbulence and vortexes created by helical curves. Since the efficiency of spiral tubes in case of thermal performance is higher, this study focused on EGR with spiral tube.

Figure 9 shows the effect of hot gas mass flow rate on gas and coolant regions. Heat transfer in coolant and gas region is likely the same which proves the energy balance 


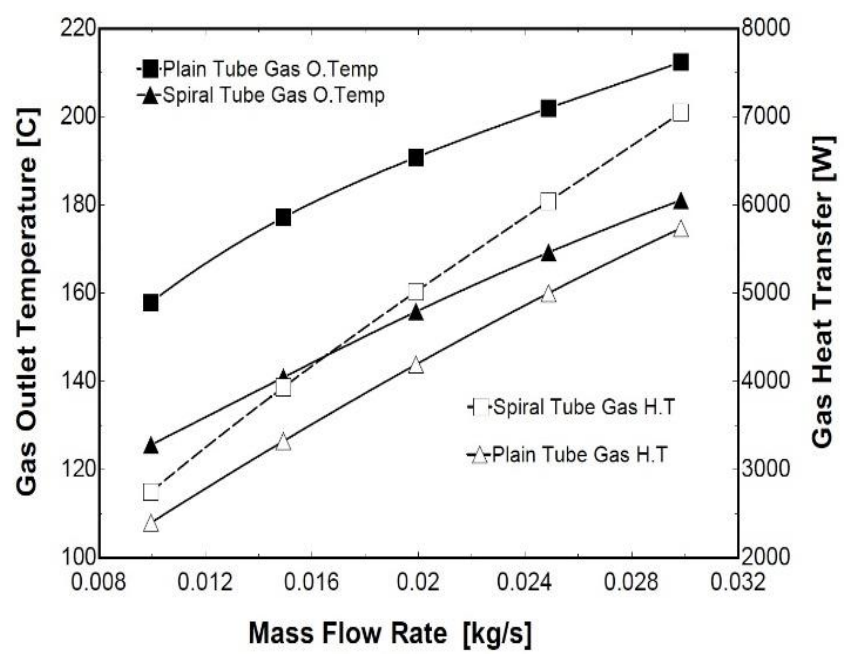

Figure 8. The Cmparison between of EGR with Spiral Tube and Plain Tube

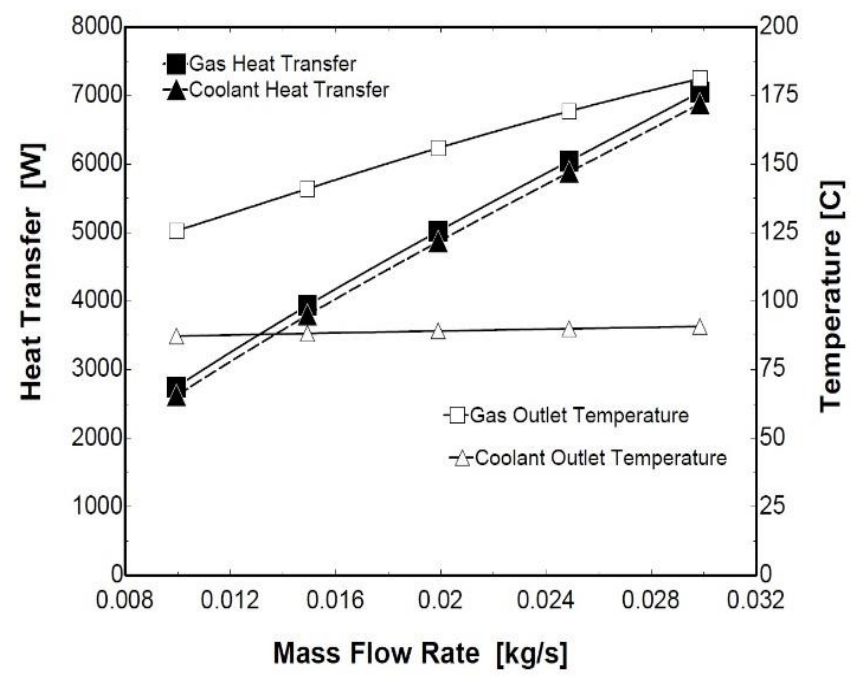

Figure 9. Hot Gas Mass Flow Effect

through EGR. It is notable that the range of coolant outlet temperature doesn't change much as the mass flow rate in gas region increases. This might be happening because of the higher heat capacity of coolant which will prevent the temperature to increase and it remains constant.

Figure 10 illustrates the effect of coolant mass flow rate on the EGR with spiral tube performance. Coolant and gas outlet temperatures fairly decrease with any increase in mass flow rate yet still the temperature difference is not big enough. While the heat transfer gradient for both coolant and gas regions increases proportionally for about $500 \mathrm{~W}$, in both cases. It seems that any change in coolant region mass flow will affect the EGR performance yet these effects are not considerable to that of gas region.

Simulated EGR is based on parallel flow arrangement, thus another simulation performed in order to investigate the effect of counter flow. Results showed a slight difference in gas outlet temperature with the reduction of $2{ }^{\circ} \mathrm{C}$ in counter flow arrangement. Meanwhile the 


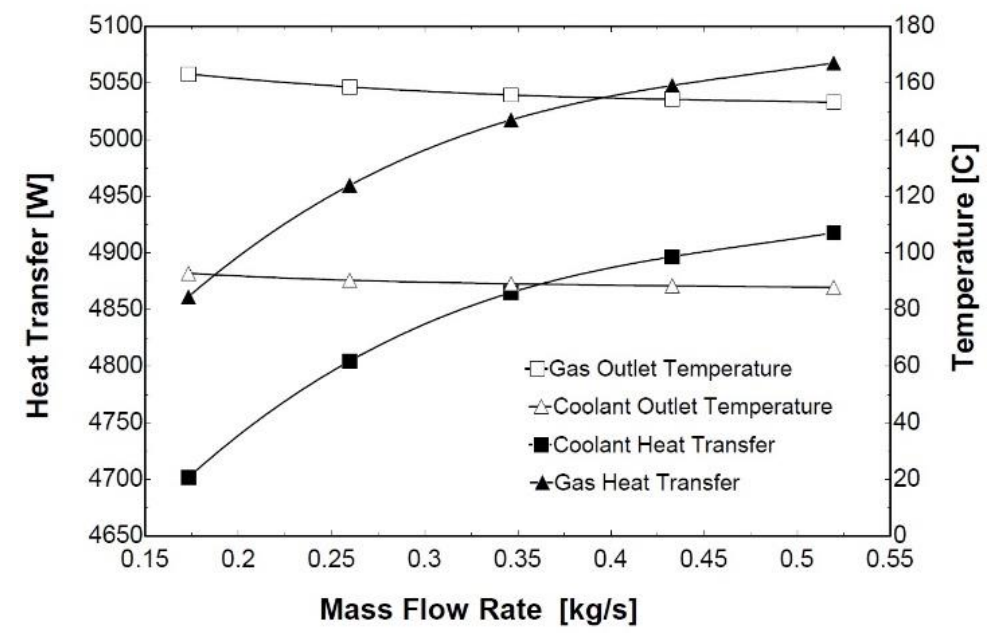

Figure 10. Coolant Mass Flow Effect

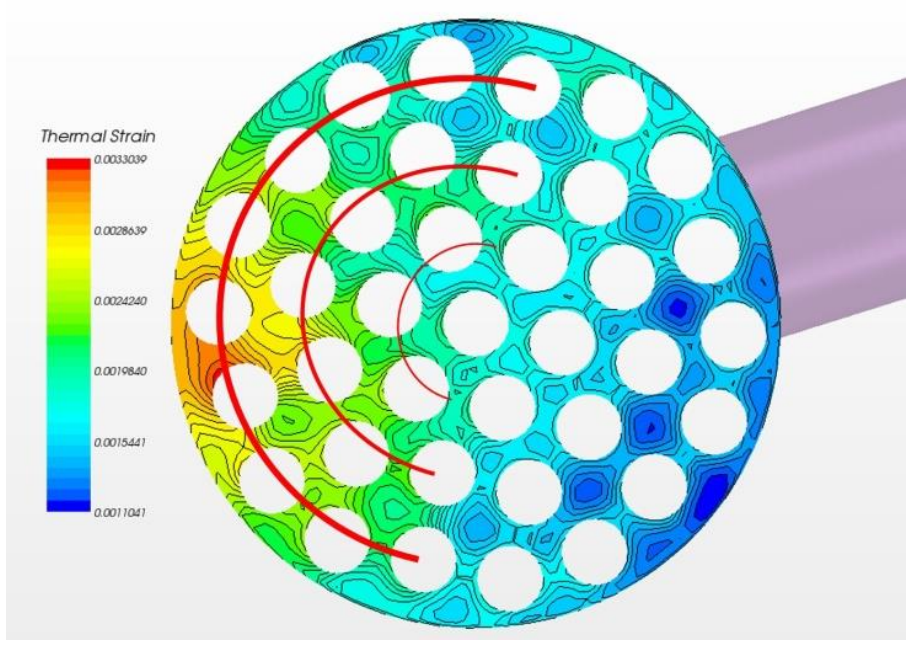

Figure 11. Thermal Stress Distribution on Header

quantity of heat transfer increased as expected. In the case of coolant temperature there is not a considerable change in temperature and heat transfer. As a matter of fact, the performance in counter flow should be better, this phenomenon is observed in simulation as well yet there is not a significant effect. This could be happening due to the short tube length and the scale of EGR in compare to an industrial heat exchangers.

Figure 11 illustrates the thermal strain on the inlet header on three different half circles from bottom to top, while Photo.2 demonstrate the same header on the actual EGR. Experimental results show that there is a high possibility of the cracks appearance on the left down side of the header due to the thermal shock effects. CFD result in Figure 11 also proves that the mentioned area is at a high risk of thermal strain due to the higher temperature difference and lower mass flow rate. It is distinctively observed in Figure 12 that the higher thermal stress may happen in the outer half circle and it decreases as it shifts down closer toward the center of the header, to the point that the minimum happens at the inner half circle. 


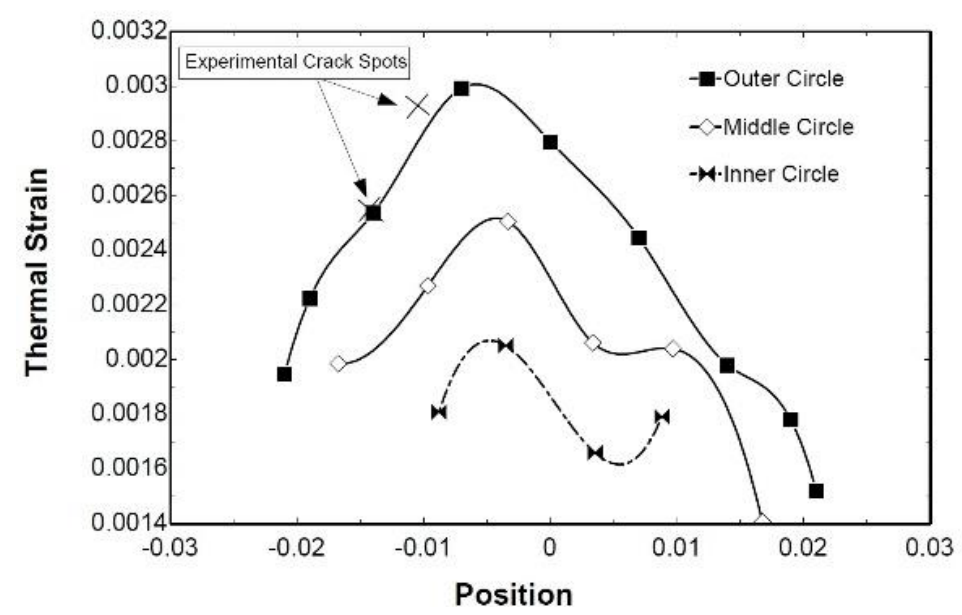

Figure 12. Thermal Stress Distribution on Header

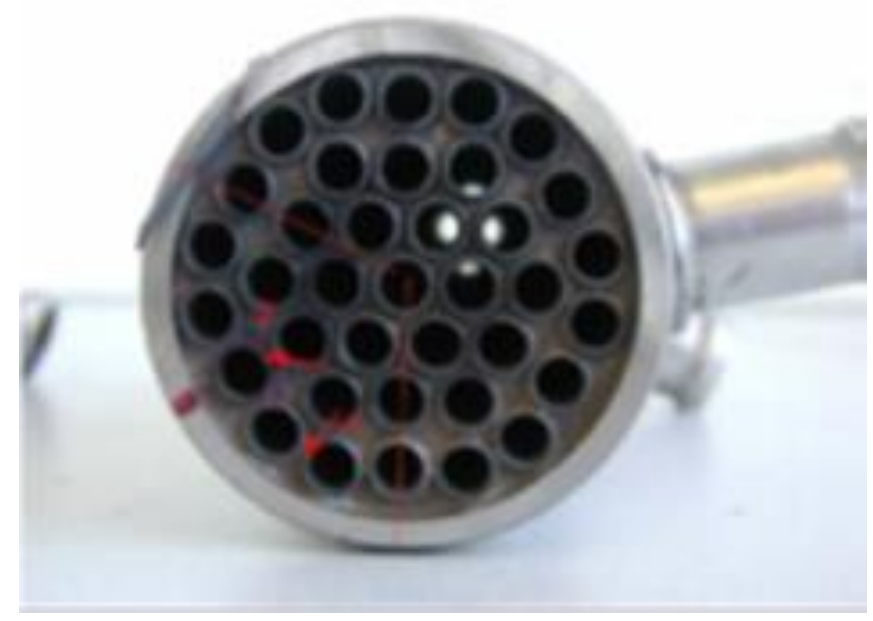

Photo 2. Crack Locations on Header

Maximum points are totally in agreement with the experimental crack locations pointed out on the Photo.2. One of the crack points predicated is coincides with the experimental result and the other one, although there is small difference in prediction, yet the maximum thermal strain area is located at the same spot which means the crack could happen almost anywhere at that specific area.

\section{Conclusion}

An EGR with spiral and plain has been simulated using commercial CFD software STAR-CCM+ Version 9.0 in order to maintain the flow behavior in EGR under specific circumstances. To validate the CFD results, it was compared to the experimental result. Errors found less than 5\% which proves that the simulation results are eligible in order to perform parametric study. 
The comparison between EGR with spiral and plain tube proved that the spiral type due to the higher turbulence ratio provides average $16 \%$ higher heat transfer rate rather than plain tube, yet the second type behaves more reasonable in case of pressure drop and flow resistance.

Mass flow rate increment in both regions led to higher thermal performance as a result lower hot gas outlet temperature. But due to a higher capacity in coolant region, this effect was less egregious in coolant region in compare to that of gas region.

It has been shown that the EGR with counter flow arrangement provides better heat transfer although in this case the different is not tremendous. The thermal strain has been investigated on the inlet header of the EGR and compared to the actual crack spots in experiment. The results were totally capable of predicting the high risk crack area and the crack spots were predicted precisely which let us to predict the behavior of EGR. Thus any parametric study can be done in order to improve the efficiency or lowering the possibility of thermal cracks appearance.

\section{Acknowledgements}

This work was supported by the "Human Resource Development (project name: Advanced track for Si-based solar cell materials and devices, project number: 20124030200080)" of the Korea Institute of Energy Technology Evaluation and Planning (KETEP) grant funded by the Korea government Ministry Trade, Industry and Energy. This paper was also partially supported by Automobile High Technology Research Institute of Chonbuk National University.

\section{References}

[1] KI. Agrawal, S. K, Singh, S. Sinha and M. K. Shukla, “Sadhana”, Springer India, vol. 29, no. 3, (2004).

[2] J. Hilliar and R. Wheeler, "SAE Technical Paper", 790691, (1979).

[3] H. Wei, T. Zhu, G. Shu, L. Tan and Y. Wang, J. Applied Energy 99, (2012).

[4] M. Zheng, G. T. Reader, J. G. Hawley, J. Applied Energy, vol. 99, (2012).

[5] T.Murayama, M. Zheng, T. Chikahisa, Y.-T. Oh, Y. Fujiwara, S. Tosaka, M. Yamashita and H. Yoshitake, SAE Technical Paper, 952518, (1995).

[6] D. Tomazic, and A. Pfeifer, SAE Technical Paper, (2002).

[7] A. Wang, X.Tang and H. He, "Thermodynamic simulation of exhaust gas recirculation coolers used on diesels based on finite element method", System Simulation and Scientific Computing, Asia Simulation Conference - 7th International Conference, (2008) October 10-12; Beijing, China.

[8] R. Florea, D. Taraza, N. Henein and W. Bryzik, SAE Int. J. Engines, vol. 1, no. 1, (2009).

[9] F. Vashahi, M. Lee, J. Kim and B. J. Baek, "Thermal and Strain Characteristics of EGR Cooler",3rd International Workshop on Mechanical Engineering, (2014) April 16-18; Jeju island, Korea.

[10] D. C. Wilcox, “Turbulence Modelling for CFD (3rd ed.)”, Dcw Industries Inc., La Canada, (2006).

[11] STAR-CCM+ Version 9.0 user manual

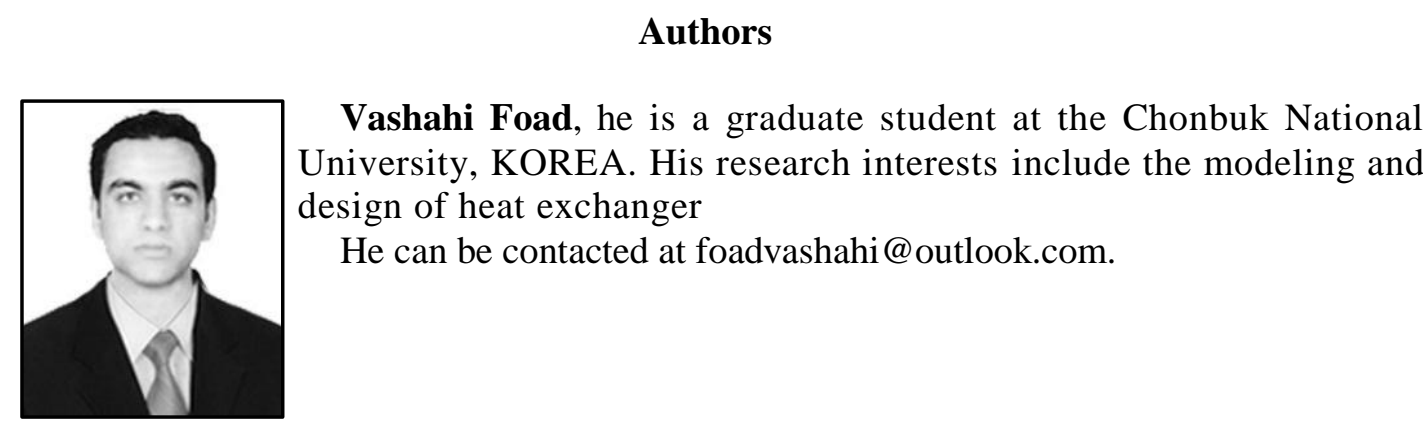




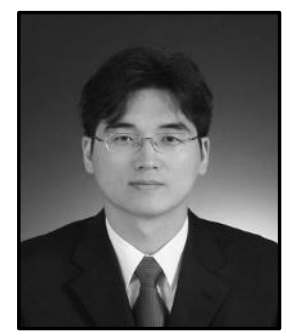

Myung-Jae Lee, he is a graduate student at the Chonbuk National University, KOREA. He received the M.S. degree from Chonbuk University in 1993. His research interests are design of heat exchanger and optimum design.

He can be contacted at saenal91@naver.com.

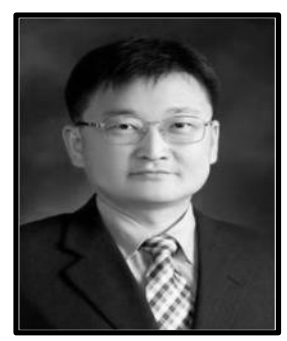

Jin-Taek Kim, he received the B.S., M.S. and Ph. D. degree in mechanical engineering from Chonbuk National University, Republic of Korea in 1991, 1994 and 2001, respectively. His research interests are electronic equipment Cooling system and LED thermal radiation analysis.

He can be contacted at kjtaek@jbnu.ac.kr.

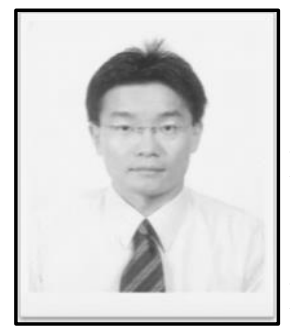

Dae-Suk Kim, received his $\mathrm{PhD}$ in Mechanical Engineering from Korea Advanced Institute of Science \& Technology in 2002. He was a postdoctoral associate at Department of Electrical \& Computer Engineering, University of Connecticut in USA till 2004. Also, he worked for Samsung Electronics by 2007. From May 2007, he is working as an assistant professor at Division of Mechanical System Engineering in Chonbuk National University in Korea. For the last 15 years, his major interests have been in opto-mechatronics for micro nano regimes which included real time phase sensitive optical metrology, 3D imaging and display, opto-electronic devices such as high brightness LED and ultra-precision actuation systems. Recently, he is focusing on single shot based phase measurement fields containing new concepts on digital holography and spectroscopic ellipsometry. He can be contacted at dashi.kim@jbnu.ac.kr.

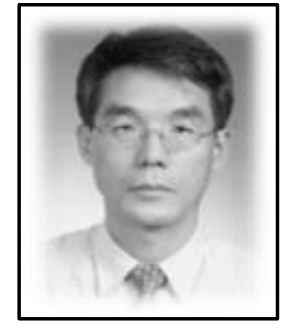

Byung-Joon Baek, he received the M.S. degree from Seoul University in 1981, and the Ph.D. degree from Missouri-Rola University in 1990. he is currently at the Division of Mechanical Engineering System, Chonbuk National University, KOREA. His research interests include the modeling and analysis for the thermal/mass transfer for the efficient thermal processing system. $\mathrm{He}$ is the corresponding author and can be contacted at baekbj@jbnu.ac.kr. 